\title{
Influence Factors of Vibration Response on Supporting-Thrusting System of Tunnel Boring Machine
}

\author{
Yongbing Mei, ${ }^{1,2}$ Yimin Xia $\mathbb{D D}^{1,2}$ Laikuang Lin ${ }^{1}{ }^{1,2}$ Yongliang Cheng, ${ }^{3}$ and Cong Qian ${ }^{1,2}$ \\ ${ }^{1}$ College of Mechanical and Electrical Engineering, Central South University, Changsha 410083, China \\ ${ }^{2}$ State Key Laboratory of High Performance and Complex Manufacturing, Changsha 410012, China \\ ${ }^{3}$ China Railway Construction Heavy Industry Co. Ltd., Changsha 410100, China \\ Correspondence should be addressed to Laikuang Lin; linlaikuang@csu.edu.cn
}

Received 14 February 2020; Revised 6 July 2020; Accepted 9 July 2020; Published 29 July 2020

Academic Editor: Rafał Stanisławski

Copyright (c) 2020 Yongbing Mei et al. This is an open access article distributed under the Creative Commons Attribution License, which permits unrestricted use, distribution, and reproduction in any medium, provided the original work is properly cited.

A supporting-thrusting system is the main load-bearing component of a tunnel boring machine (TBM) and the centralization of vibration response under TBM working. This study combines the structure and working principle of the supporting-thrusting system. Based on the vibration theory and test results at a construction site, the main influence factors of the vibration response of the supporting-thrusting system are the main beam structure, the characteristic parameters of advance cylinder, and the support pressure to surrounding rock. Under the different influence factors, the vibration response of the supporting-thrusting system is calculated and analyzed via computer simulation. The results indicate that, under the equivalent input-load on the TBM and increase in the length of the front main beam, the vibration acceleration at the front area of the TBM increases. The change rate of vertical vibration will be maximum, while the vibration acceleration at the rear area of TBM decreases. When the structure size of the thrusting cylinder increases, the vibration acceleration on the main beam decreases and those of the gripper shoe and saddle frame increase. However, the response to the axis vibration is the most sensitive. As the horizontal support pressure to the surrounding rock increases, the vibration acceleration on supporting-thrusting system decreases. When the level of support pressure exceeds $1.6 e 4 \mathrm{kN}$, the vibration acceleration changes gradually. These results provide a reference for designing and operating TBM parameters.

\section{Introduction}

A full-face tunnel boring machine (TBM) is the key excavating equipment in hard rock-based tunnel construction. The TBM plays an important role in tunnel constructions such as the railway, highway, water conservancy, and municipal administration [1-3], Engineering geology is an important factor that affects the TBM driving efficiency. Rock formations with moderate rock strength and good integrity are more suitable for TBM construction, and lithology includes granite, limestone, conglomerate, and sandstone. But the soft soil layer with poor self-stability cannot meet the TBM construction. As the skeleton of the TBM, the supporting-thrusting system comprises a shield, main beam, saddle, gripper shoes, and other parts. During the process of tunneling, the cutterhead bears the heavy fluctuating load, which is transmitted to parts such as the main beam, saddle, and gripper shoes and causes the vibration of entire supporting-thrusting system [4]. On the one hand, the heavy mechanical vibration generates high dynamic stresses in the mechanical parts of the TBM and the abnormal operation of other equipment and can even cause the failure of components or accidental shutdown. On the other hand, the high vibration response will cause TBM stability loss or gripper shoe slipping when the TBM supports the surrounding rock at the horizontal level [5-7]. This directly affects the stability and safety of TBM tunneling process.

Currently, concerning TBM load and vibration performance, scholars placed research emphasis on parts such as the cutterhead, cutters, and main drive. Festa et al. [8] studied the influential factors for thrust and torque of the 
cutterhead and established a computation formula for external loads such as the torque, thrust, and overturning moment. Huo et al. [9] discussed the effect of different factors including the rotation speed of the cutterhead, cutterhead topology, speed fluctuation, and nonsynchronization of small driving gears on the vibration characteristics of cutterhead based on the multibody system dynamics simulation platform ADAMS. In addition, Huo et al. [10] also established 3D models of both horizontal and vertical directions to evaluate the vibration characteristics of disc cutter and node displacement-time curves of vibration. Ling et al. [11] studied the translating-reversing-overturning multiple degrees-of-freedom coupled dynamic model of the TBM cutterhead system and determined the effects of cutterhead system parameters on the inherent frequency and issue of sensitiveness. Sun et al. [12] proposed a TBM cutterhead driving system dynamic model with the generalized hierarchical modeling method and explored the influence laws of the coupling parameters on the dynamic response of the cutterhead driving system. Concerning aspects of the dynamic transfer and response of the TBM supporting-thrusting system, Hassanpour et al. [13] studied the dynamic characteristics of the TBM supportingthrusting system under different geological conditions and obtained the relationships between the cutterhead's rotational speed, thrust, and advance speed. Wu et al. [14] obtained the dynamic speed rigidity, static speed rigidity, and minimum speed rigidity of a TBM thrust hydraulic cylinder based on a typical cylinder controlled by the reducing valve. Huang et al. [15] proposed a mechanical analytical method of an open-type TBM supportingthrusting system, established the cutterhead-main-beamsaddle static equilibrium equation, and obtained the mapping relationship between the thrust propelling the hydrocylinder and the hydrocylinder force applied on the shield. Yu et al. [16] obtained the correlation between the normal contact stiffness and the loads, which considers parameters such as the roughness of the tunnel surfaces, the mechanical behaviour of rocks, the number of the supporting boots, and composite geologic structures. Xie and $\mathrm{Yu}$ [17] studied the stiffness of the surface between gripper shoes and rocks, and the results demonstrated that stiffness increases with the enlargement of loads on the cutterhead. Huang et al. [15] presented an approach for force analysis of gripping-thrusting-regripping mechanism (GTRM) of an open TBM. At present, scholars' dynamics research on TBM supporting-thrusting system mainly focuses on load transfer and modeling, stiffness characteristics, etc., but there is less research on vibration characteristics and influencing factors.

In this study, by combining the test results obtained at a project site through structural analysis and simulation calculation, the vibration response of a TBM supportingthrusting system and its influencing factors are studied. The research results will be useful in guiding TBM product design and construction [18].

\section{Vibration Effect of TBM Supporting- Thrusting System}

TBMs can be classified into the open-type TBM and shield TBM. The supporting-thrusting system is the crucial loadbearing component of the open-type TBM. In the design, cutter head 1 in front of the TBM and main drive 9 are connected with the construction auxiliary equipment at the back, which achieves structural connectivity, load transfer, and energy supply (shown in Figure 1). The supportingthrusting system is part of the TBM mainframe machine, which mainly consists of structures such as shield 2, front main beam 3 , middle main beam 4 , thrusting cylinder 8 , and horizontal support device (including saddle 5, supporting cylinder 6, and gripper shoe 7). When the TBM moves forward during the tunneling, the external wall of the shield is in contact with the surrounding rock of the tunnel, as shown in Figure 2. The external wall does not only bear the weight of TBM mainframe machine and a small part of the rotating torque but also offers protection to the operators and equipment. The thrusting cylinders at both sides of the main beam provide the TBM with the forward momentum. The main beam is of hollow, long, and narrow structure, with its front part fixed on the central position of the TBM mainframe machine. The gripper shoes, support cylinder, and saddle included by the horizontal support device are arranged at both sides of the main beam, which produce frictional force with the gripper shoes, tightly supporting the surface of the surrounding rock. This action provides a reverse thrust to the TBM tunneling and actions of the thrusting cylinder. Meanwhile, the horizontal support device can be axially glided along both sides of the main beam to accommodate the extension or retraction of the thrusting cylinder. The coordinate directions quoted in this study are the $X$-, $Y$-, and $Z$-axes, which represent the horizontal direction, the longitudinal or vertical direction, and the central axis direction of the tunnel, respectively [4].

From the structural distribution of the TBM mainframe machine, the vibration from the frontal part of the TBM mainframe machine is transmitted to the parts at the rear area of the machine, which further triggers the vibration response of the supporting-thrusting system. The shield and horizontal support device are only two fulcrums between the TBM mainframe machine and surrounding rock. According to the vibration theory, the distance between two fulcrums and the stability of the fulcrums will impose a significant impact on the vibration response of the TBM supporting-thrusting system. Considering the TBM equipment state and test conditions, the vibration acceleration parameter is used to indicate the vibration response of all the parts of the supporting-thrusting system during the TBM tunneling in the actual project. The parameter indicated a better reflection of the impact force of the sudden changes in the load on the TBM equipment when the cutterhead breaks the rock. 


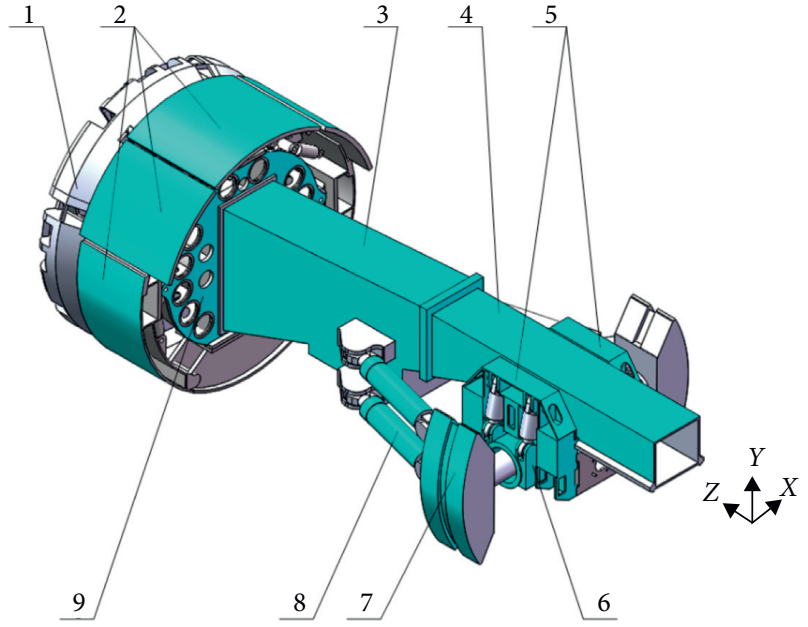

FIgURE 1: Structural drawing of TBM mainframe machine. (1) Cutterhead, (2) shield, (3) front main beam, (4) middle main beam, (5) saddle, (6) support cylinder, (7) gripper shoes, (8) thrusting cylinder, and (9) main drive.

A TBM applied to the tunnel project for irrigation works in Jilin of China was chosen as the test object. The total length of this tunnel was $72 \mathrm{~km}$, and three machines of TBM with the excavation diameter of $7.93 \mathrm{~m}$ were adopted. The buried depth of the tunnel was between 30 and $550 \mathrm{~m}$. The rock types comprised granite, sandstone, tuff, and glutenite, with compressive strength values ranging from 40 to $130 \mathrm{MPa}$. Grades II and III accounted for $84.3 \%$, and a small part of the fault and structured strata also exists among them. To obtain reasonable experimental data, the vibration tests were completed during the TBM tunneling operations in the stable granite and set up using specified working parameters (as shown in Table 1). The average accelerations of vibration on the main beam and horizontal support device were $4.11 \mathrm{~m} / \mathrm{s}^{2}$ and $0.67 \mathrm{~m} / \mathrm{s}^{2}$, respectively. The test period was $60 \mathrm{~s}$, and the sampling frequency was $10.24 \mathrm{kHz}$ (Figures 3 and 4).

Moreover, in terms of vibration response, there was a significant difference between different areas such as the frontal part of the main beam (area of shield), the middle part of the main beam (working area of thrusting cylinder), and the horizontal support device. The test results showed the vibration response laws of the structural design characteristics of the TBM supporting-thrusting system under the exciting force when the cutterhead was operated. To analyze the differences between the different influential factors of vibration response, this study takes the structural length of the main beam, the size of the thrusting cylinder, and the support pressure as the objects of analysis. A computer simulation was adopted, and the input conditions of calculation were also set according to Table 1. Under the same condition of exciting force, the vibration response of all the structures with varying parameters was calculated. The results provided a theoretical reference data for the optimization of TBM structural design scheme and supervision. The vibration response on the TBM support thrusting system was studied by computer simulation following the main steps: (1) a three-dimensional structure model of the TBM support thrusting system was established according to the simulation software analysis. (2) Use ANSYS software to apply load to the cutterhead, main drive, main beam, and other components and obtain the maximum deformation of each component (Figure 5). According to Hooke's law, the equivalent structural rigidity of each component can be calculated.

Additionally, the equivalent stiffness of each hydraulic cylinder was calculated based on the fluid transmission theory. The equivalent contact stiffness between the gripper and surrounding rock, shield, and surrounding rock was obtained from the Hertz theory and M-B fractal contact model. (3) After that, the equivalent damping of each component was calculated based on the equivalent stiffness and equivalent mass of each component. (4) The structure model of the cutterhead was imported into the ANSYS software. Its simulation model for rock-breaking of the disc cutter based on the HJC constitutive relations was established $[19,20]$. After setting the penetration to $6 \mathrm{~mm}$ and cutterhead speed to $5 \mathrm{rpm}$ and selecting granite as the rock category, the dynamic loads on the TBM were obtained by simulation. (5) The three-dimensional structure model of the TBM supporting-thrusting mechanism was imported into the ADAMS software for the dynamics simulation, completing the physical parameters (stiffness, damping, and mass) of model setting, flexible joint constraints and structural motion constraints appending, and dynamic loads loading in proper sequence (Figure 6). Afterwards, the vibration was simulated, and the parameters of vibration acceleration on each part of the TBM supporting-thrusting system under different conditions were obtained.

\section{Main Beam}

Considering the needs for transport, installation, and space layout in the TBM structural design, the structure of the main beam generally uses the three-section design of front, middle, and rear. The bolted connection was adopted between each section of the main beam. Considering that the length and quality of the front main beam are much larger than the middle main beam and the rear main beam, therefore, in this study, the analysis and calculation were performed with the structural parameters of the front main beam as one of the influential factors of the vibration response of the supporting-thrusting system. The design structure of the front main beam is shown in Figure 7.

For the structural parameters of the TBM with $8 \mathrm{~m}$ diameter, five group lengths of the front main beam were referenced, that is, $6.45,6.95,7.45,7.95$, and $8.45 \mathrm{~m}$, respectively. As the values varied, the front main beam quality, equivalent stiffness, and equivalent damping were calculated with different lengths (Table 2). The results show that when the length of the front main beam increases by $31 \%$, the quality of the front main beam increases by $20 \%$. Both the equivalent stiffness and equivalent damping gradually reduced: for the equivalent stiffness, the maximum reduction was $58 \%$ (longitudinal), and the minimum reduction was $29 \%$ (reverse); correspondingly, the maximum and 


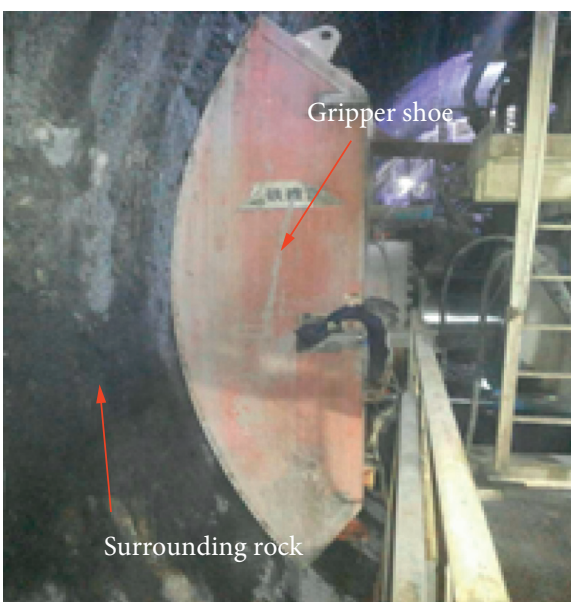

(a)

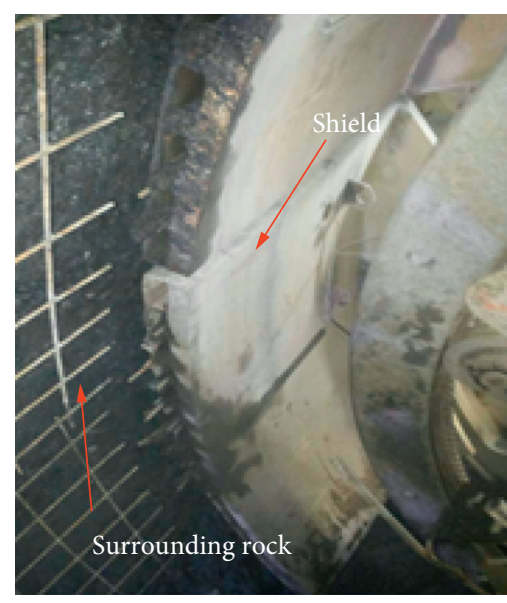

(b)

FIGURE 2: TBM gripper shoes and shield under working condition.

TABLE 1: Working condition of one TBM tunnel and its tunneling parameters.

\begin{tabular}{lccccc}
\hline $\begin{array}{l}\text { Types of } \\
\text { rock }\end{array}$ & $\begin{array}{c}\text { Rock mass strength } \\
(\mathrm{MPa})\end{array}$ & $\begin{array}{c}\text { TBM excavation diameter } \\
(\mathrm{m})\end{array}$ & $\begin{array}{c}\text { Rotational speed of cutterhead } \\
(\mathrm{rpm})\end{array}$ & $\begin{array}{c}\text { Penetration } \\
(\mathrm{mm})\end{array}$ & $\begin{array}{c}\text { TBM thrust force } \\
(\mathrm{kN})\end{array}$ \\
\hline Granite & $90 \sim 130$ & $\Phi 7.93$ & 5.0 & 6 & 10,500 \\
\hline
\end{tabular}

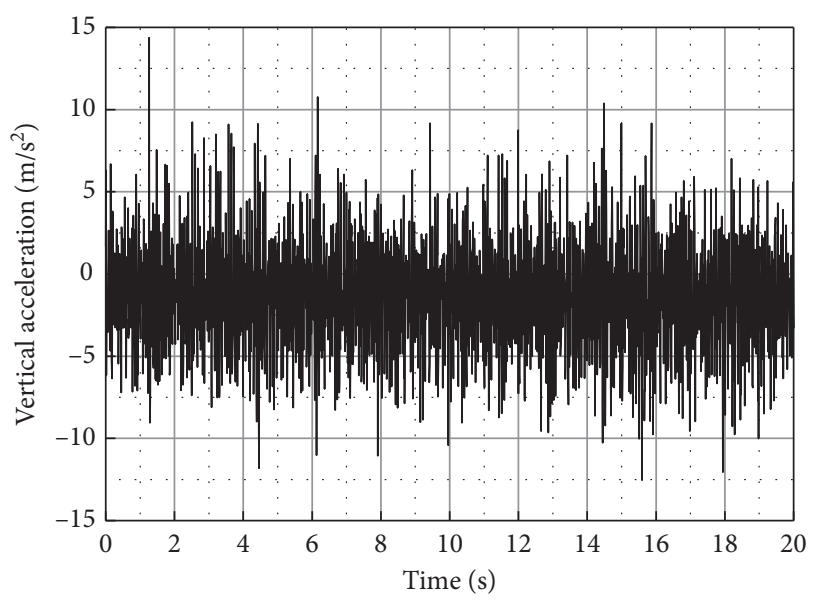

FIgURE 3: Testing value of vibration acceleration on main beam.

minimum reduction of the equivalent damping were $31 \%$ (longitudinal) and 13\% (reverse), respectively.

The front main beam, middle main beam, saddle, and gripper shoes were selected as the test points of vibration response of the supporting-thrusting system. The simulating calculation was performed for the vibration response when the length of the front main beam increased continuously. The results indicate that as the length of the front main beam increased, the longitudinal equivalent stiffness value of the front main beam decreased by $58 \%$. As a result, the vibration acceleration of the self-structure in the $Y$-axis increases from $3.52 \mathrm{~m} / \mathrm{s}^{2}$ to $4.4 \mathrm{~m} / \mathrm{s}^{2}$, representing a $31 \%$. However, since the change in length has a relatively small change in the equivalent stiffness in the $X$ and $Z$ directions of the front main beam, there was no significant effect in the vibration

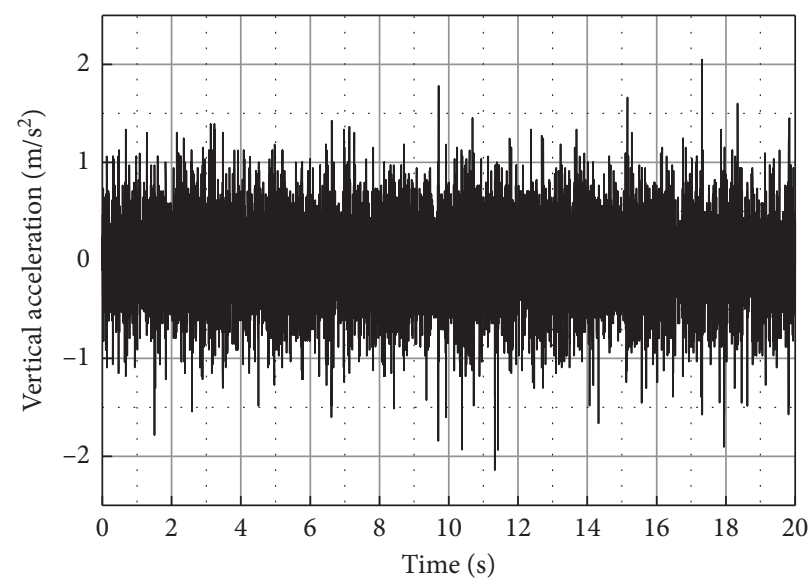

FIgURE 4: Testing value of vibration acceleration on gripper shoes.

acceleration at the $X$ - and $Z$-axes. As the length of the front main beam increased, the parts such as the middle main beam, saddle, and gripper shoes moved farther from the positions of the exciting force. The front main beam used more vibration energy, which caused the vibration acceleration of the position structure in the rear area of the supporting-thrusting system to display a generally decreasing trend, in which the decreasing range of the saddle was the most significant. Under the action of the support cylinder, the gripper shoes tightly supported the surrounding rock, and its absolute value of vibration acceleration was the lowest (the maximum value at the $Z$-axes was $1.83 \mathrm{~m} / \mathrm{s}^{2}$, and the minimum value at the $Y$-axes was $0.55 \mathrm{~m} /$ $\mathrm{s}^{2}$ ). The changing range of vibration acceleration on the gripper shoes was also the lowest, and with the increase of 


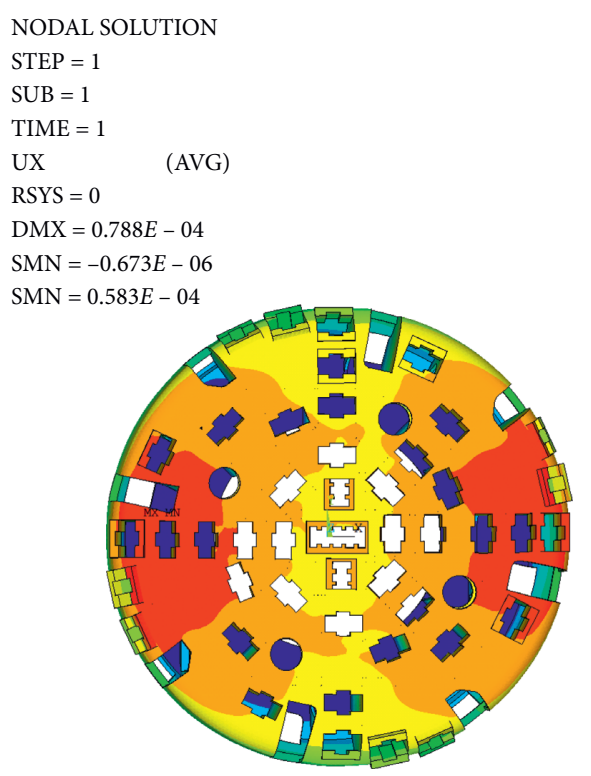

(a)

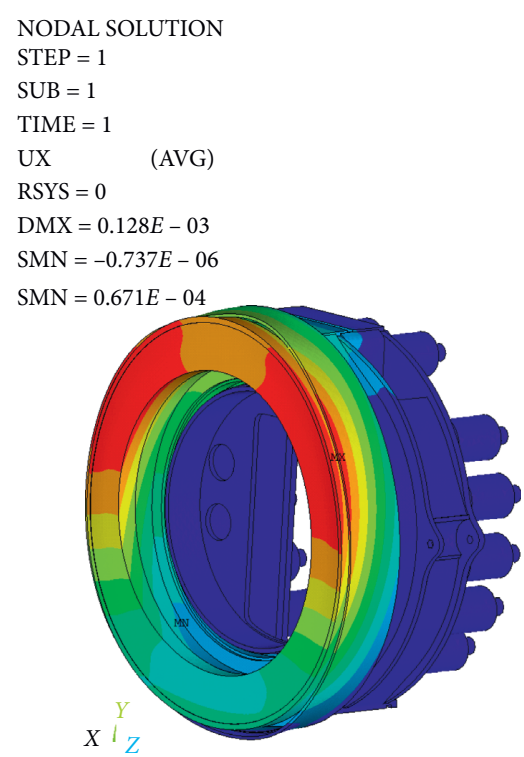

(b)
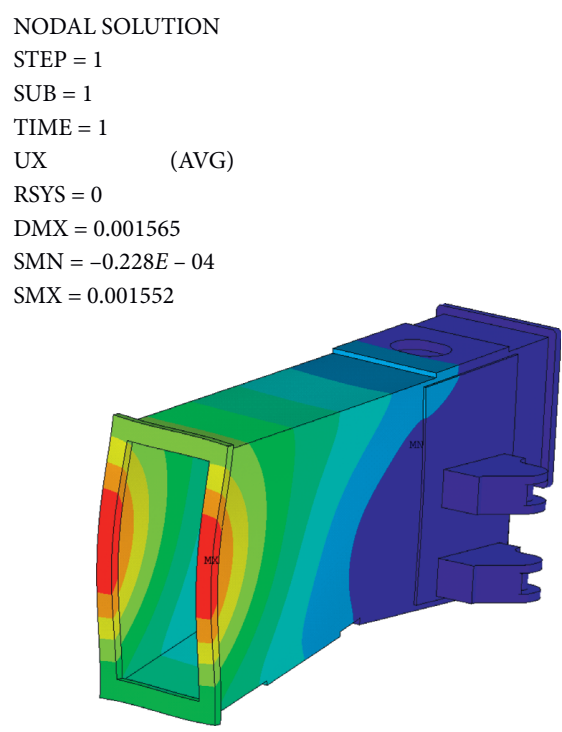

(c)

FIGURE 5: Finite element calculation of structural stiffness of components.

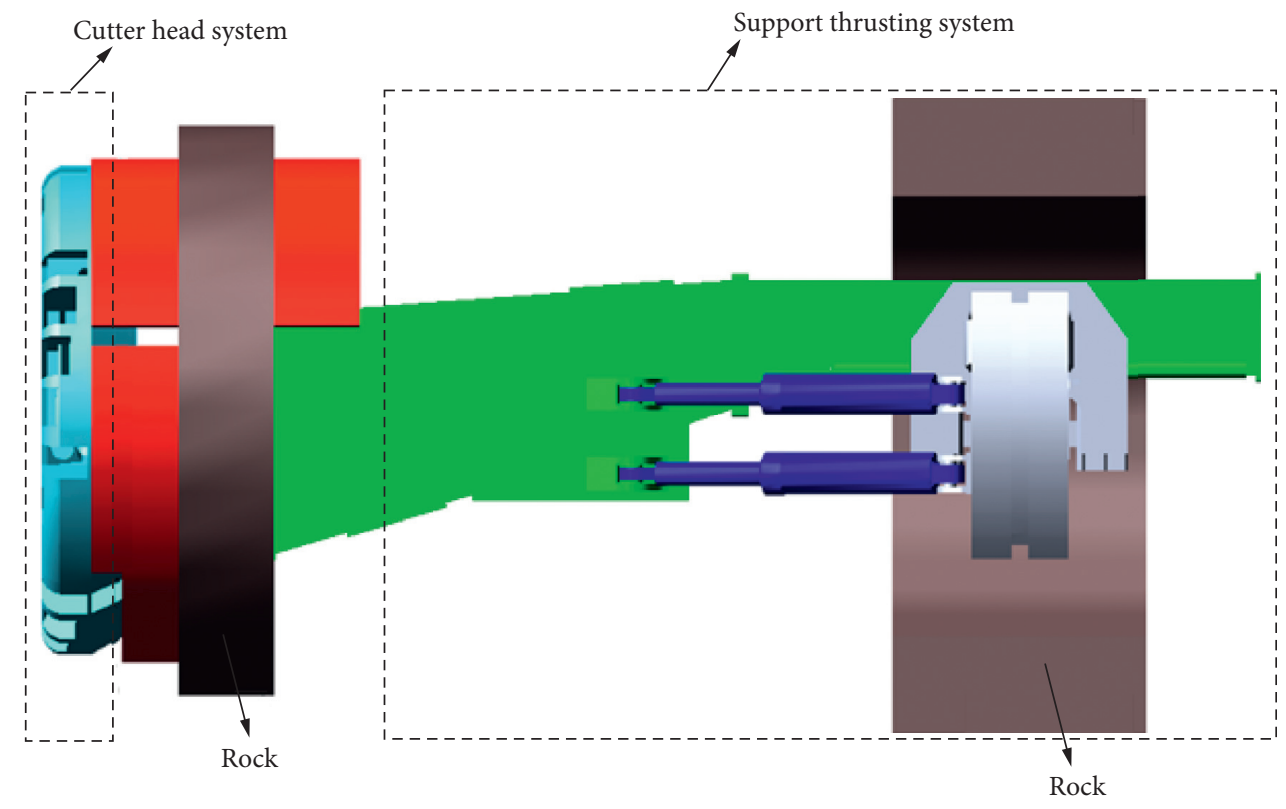

FIGURE 6: Vibration acceleration simulation.

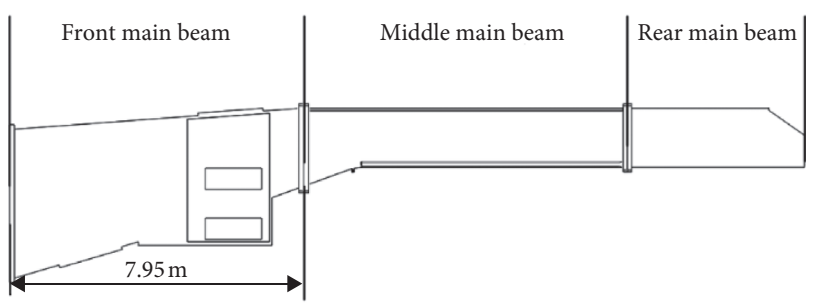

FIGURE 7: Structure of main beam. the length of the front main beam, in addition to the front main beam, the vibration acceleration of the three components of the middle main beam, the saddle frame, and the support shoes all show a slight downward trend (Figure 8).

\section{Thrusting Cylinder}

The thrusting cylinders were the main bodies of the TBM propulsion device, which was inclined at approximately $15^{\circ}$ to the centerline of the tunnel ( $Z$-axis). Both ends of the 
TABLE 2: Characteristic parameter of main beam of different length.

\begin{tabular}{|c|c|c|c|c|c|c|c|c|c|}
\hline \multirow[b]{2}{*}{$\begin{array}{l}\text { Length of front main } \\
\text { beam }(\mathrm{m})\end{array}$} & \multirow{2}{*}{$\begin{array}{l}\text { Quality } \\
\text { (kg) }\end{array}$} & \multicolumn{4}{|c|}{ Equivalent stiffness $(\mathrm{N} / \mathrm{m})$} & \multicolumn{4}{|c|}{ Equivalent damping $(\mathrm{N} \cdot \mathrm{s} / \mathrm{m})$} \\
\hline & & $\begin{array}{l}\text { Lateral } \\
(X)\end{array}$ & $\begin{array}{l}\text { Longitudinal } \\
(Y)\end{array}$ & $\begin{array}{c}\text { Axial } \\
(Z)\end{array}$ & Reverse & $\begin{array}{l}\text { Lateral } \\
\qquad(X)\end{array}$ & $\begin{array}{l}\text { Longitudinal } \\
(Y)\end{array}$ & $\begin{array}{l}\text { Axial } \\
(Z)\end{array}$ & Reverse \\
\hline 6.45 & $6.61 e 4$ & $4.65 e 8$ & $1.51 e 9$ & $1.19 e 10$ & $3.99 e 10$ & $2.34 e 5$ & $4.21 e 5$ & $1.18 e 6$ & $2.16 e 6$ \\
\hline 6.95 & $6.99 e 4$ & $4.25 e 8$ & $1.32 e 9$ & $1.14 e 10$ & $3.65 e 10$ & $2.23 e 5$ & $3.93 e 5$ & $1.16 e 6$ & $2.07 e 6$ \\
\hline 7.45 & $7.35 e 4$ & $3.87 e 8$ & $1.14 e 9$ & $1.06 e 10$ & $3.40 e 10$ & $2.13 e 5$ & $3.66 e 5$ & $1.11 e 6$ & $2.00 e 6$ \\
\hline 7.95 & $7.68 e 4$ & $3.49 e 8$ & $9.90 e 8$ & $9.53 e 9$ & $3.22 e 10$ & $2.02 e 5$ & $3.41 e 5$ & $1.06 e 6$ & $1.95 e 6$ \\
\hline 8.45 & $7.97 e 4$ & $3.03 e 8$ & $8.65 e 8$ & $8.78 e 9$ & $3.08 e 10$ & $1.89 e 5$ & $3.19 e 5$ & $1.02 e 6$ & $1.90 e 6$ \\
\hline
\end{tabular}

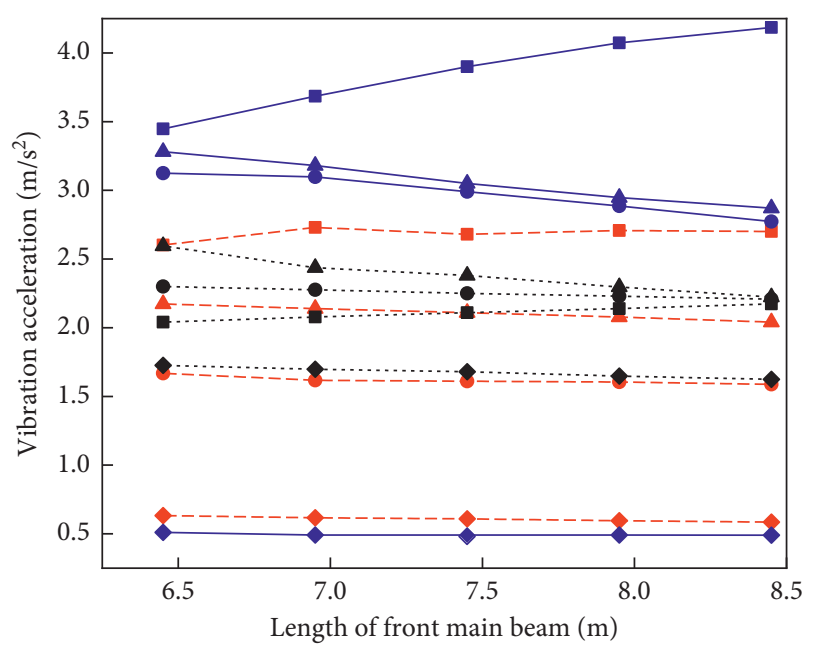

\begin{tabular}{|c|c|}
\hline -n- Main beam $X$ & -A- Saddle $X$ \\
\hline$\rightarrow$ Main beam $Y$ & $\neg$ Saddle $Y$ \\
\hline ..-.- Main beam $Z$ & ..A.- Saddle $Z$ \\
\hline - - Middle beam $X$ & $-\rightarrow$ Gripper shoe $X$ \\
\hline$\longrightarrow$ Middle beam $Y$ & $\smile$ Gripper shoe $Y$ \\
\hline .-•-- Middle beam $Z$ & .๑- Gripper shoe $Z$ \\
\hline
\end{tabular}

Figure 8: Vibration acceleration.

cylinders were fixed on both sides of the front main beam and gripper shoes. As the TBM moved forward, the thrusting cylinder was gradually extruded, and the distance between the front fulcrum (shield) and rear fulcrum (gripper shoes) was consistently increased until an excavation cycle $\Delta L$ was completed (the distance of single excavation cycle generally does not exceed $2 \mathrm{~m}$ ).

During TBM excavation, the equivalent rigidity of the thrusting cylinder changes with the change of the cylinder stroke. According to the formula calculation [21, 22], the equivalent stiffness value $k(x)$ of the thrusting cylinder at each stroke can be obtained, where the hydraulic oil elastic modulus $\beta=1.4 \mathrm{GPa}$, and the effective area of the propulsion cylinder cavity $A=\pi \times D^{2} / 4$, the initial stroke of the propulsion cylinder $L=0.15 \mathrm{~m}$, the working stroke of the thrusting cylinder $x$ :

$$
k(x)=\beta A\left[\frac{1}{L+x}\right] .
$$

Five groups of parameters, that is, $0.3,0.7,1.1,1.5$, and $1.9 \mathrm{~m}$ (strokes of thrusting cylinder $x$ ), respectively, were selected as the varying values and the equivalent stiffnesses $k(x)$ corresponding to the thrusting cylinder were calculated
TABLE 3: The equivalent stiffness of propelling oil cylinder under different thrusting strokes.

\begin{tabular}{lcc}
\hline Number & Thrusting stroke $(\mathrm{m}) x$ & Equivalent stiffness $(\mathrm{N} / \mathrm{m})$ \\
\hline 1 & 0.3 & $6.10 e 8$ \\
2 & 0.7 & $3.23 e 8$ \\
3 & 1.1 & $2.20 e 8$ \\
4 & 1.5 & $1.66 e 8$ \\
5 & 1.9 & $1.34 e 8$ \\
\hline
\end{tabular}

(Table 3). In terms of the inner diameter of cylinder barrel, $300,400,500,600$, and $700 \mathrm{~mm}$, respectively, were selected, and the equivalent stiffnesses corresponding to the thrusting cylinder were calculated (Table 4). The results demonstrated that (1) as the stroke of the thrusting cylinder increases, the piston rod of the thrusting cylinder continuously extended, which decreased the equivalent stiffness of the thrusting cylinder from $6.1 e 8 \mathrm{Nm}$ at the initial position to the $1.34 e 8 \mathrm{Nm}$ at the fully extended positions. The equivalent stiffness decreased by $78 \%$. (2) With the dimension of thrusting cylinder enlarging at $230 \%$, the equivalent stiffness of thrusting cylinder rose by $540 \%$.

From Figure 9, the simulation test results of the vibration acceleration show that as the stroke of the thrusting cylinder increases because of the decrease in equivalent stiffness of the thrusting cylinder, additionally, the front main beam gradually shifts away from the fulcrums of the gripper shoes. Thus, the vibration acceleration of the front main beam gradually increased. However, due to the vibration energy expended at the front main beam and the further distance between the rear parts and the front vibration source, the vibration acceleration values of the middle main beam, saddle, and gripper shoes significantly decreased. The range of vibration acceleration on all the parts on the $Z$-axis was maximum. The vibration accelerations on the saddle and gripper shoes were most sensitive to the stroke change on thrusting cylinder, and the variation ranges were $60 \%$ and $52 \%$, respectively, which mainly depended on the spatial layout and moving direction of the thrusting cylinder.

As shown in Figure 10, the simulation test results of vibration acceleration indicate that as the dimension of the thrusting cylinder increases, the vibration accelerations on the front main beam and middle main beam display a decreasing trend, with the largest drop at approximately $23 \%$. Moreover, when the diameter of the cylinder tube exceeded $500 \mathrm{~mm}$, the decreasing range became even more significant. As the equivalent stiffness of the thrusting cylinder increased, the vibration energy at the front of the TBM was 
TABLE 4: The equivalent stiffness of propelling oil cylinders of different specifications and dimensions.

\begin{tabular}{lcc}
\hline Number & Inner diameter of cylinder barrel $(\mathrm{mm})$ & Equivalent stiffness $(\mathrm{N} / \mathrm{m})$ \\
\hline 1 & 300 & $8.61 e 7$ \\
2 & 400 & $1.53 e 8$ \\
3 & 500 & $2.38 e 8$ \\
4 & 600 & $3.45 e 8$ \\
5 & 700 & $4.67 e 8$ \\
\hline
\end{tabular}

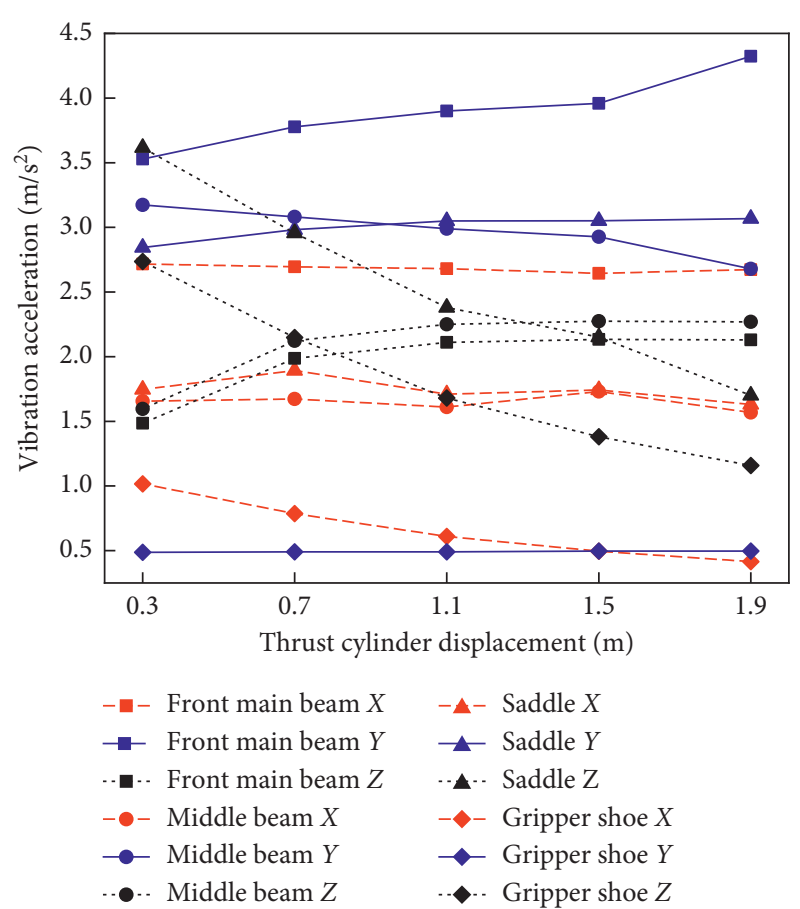

FIGURE 9: Vibration acceleration.

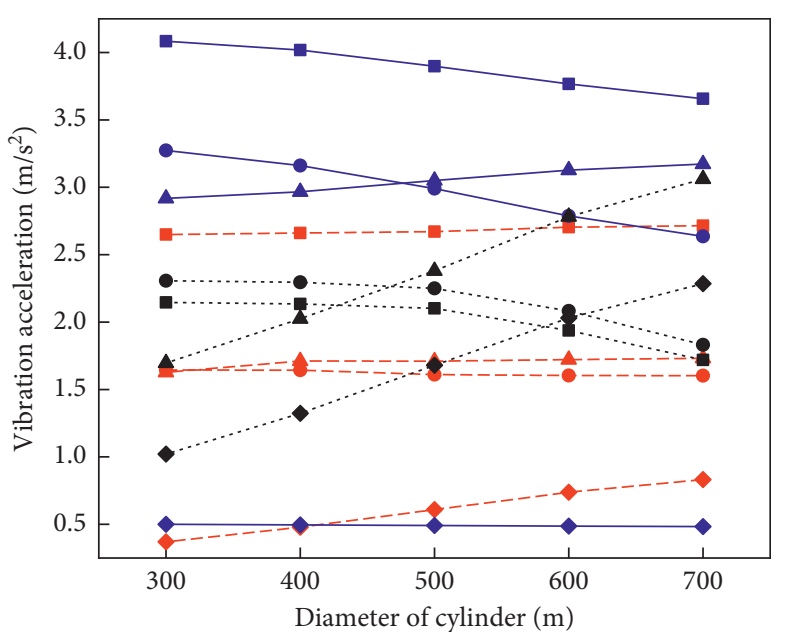

- - Front main beam $X$

$\rightarrow$ Front main beam $Y$

-... Front main beam $Z$

- - Middle beam $X$

- Middle beam $Y$

-.. Middle beam $Z$

FIGURE 10: Vibration acceleration. quickly transmitted to the gripper shoes through the thrusting cylinder. This transmission also increased the vibration acceleration values at the saddle and gripper shoes, with the maximum increase in range exceeding $100 \%$. Among them, the vibration response at the $Z$-axis was the most sensitive to the variations in the cylinder tube diameter.

\section{Support Pressure}

During the TBM tunneling process, the support pressure was mainly from the shield at the front of the main beam and the gripper shoes in the middle of the main beam (Figure 11). The support pressure of the shield mainly includes P1 caused by the weight of the main frame against the bottom-shield, P2 coming from the lateral-shield cylinder, and P3 coming from the top-shield cylinder pressure. P4 (the horizontal supporting pressure) refers to the support pressure generated by two groups of support cylinders pushing the gripper shoes (Figure 12). By taking TBM with $8 \mathrm{~m}$ diameter, the maximum design parameters for the pressure of weight with the main frame (P1), the pressure on the cylinder of the lateral-shield (P2), the pressure on the cylinder of top-shield (P3), and the horizontal supporting pressure (P4) were $6000,1000,1300$, and $22,000 \mathrm{kN}$, respectively. Considering that the $\mathrm{P} 1$ value was kept constant and P3 had a relatively smaller value, the effects of the variations in values of $\mathrm{P} 2$ and $\mathrm{P} 4$ on the vibration response of supporting-thrusting system were analyzed.

Based on the Hertz theory, the contact stiffness $k$ between the shield and the surrounding rock and between the support shoe and the surrounding rock can be calculated by formula (2) [23], where $R_{1}$ and $R_{2}$ are the radius of curvature of the contact point of the two objects, $\mu$ represents Poisson's ratio of the material in contact with the object, and $E$ represents the elastic modulus of the material in contact with the object.

$$
\left\{\begin{array}{l}
k=\frac{4}{3\left(h_{1}+h_{2}\right)}\left[\frac{R_{1} R_{2}}{R_{1}+R_{2}}\right]^{1 / 2}, \\
h_{i}=\frac{1-\mu_{i}^{2}}{E_{i}}, \quad i=1,2 .
\end{array}\right.
$$

After that, assuming five groups of data, i.e., 800, 900, 1000,1100 , and $1200 \mathrm{kN}$, as the support pressure values of the lateral shield, the corresponding contact stiffnesses on shield-surrounding rock were computed (Table 5). As the support pressure of the shield increases, the contact stiffness on shield-surrounding rock rises quickly, and the shield support pressure and contact stiffness increased by $50 \%$ and 


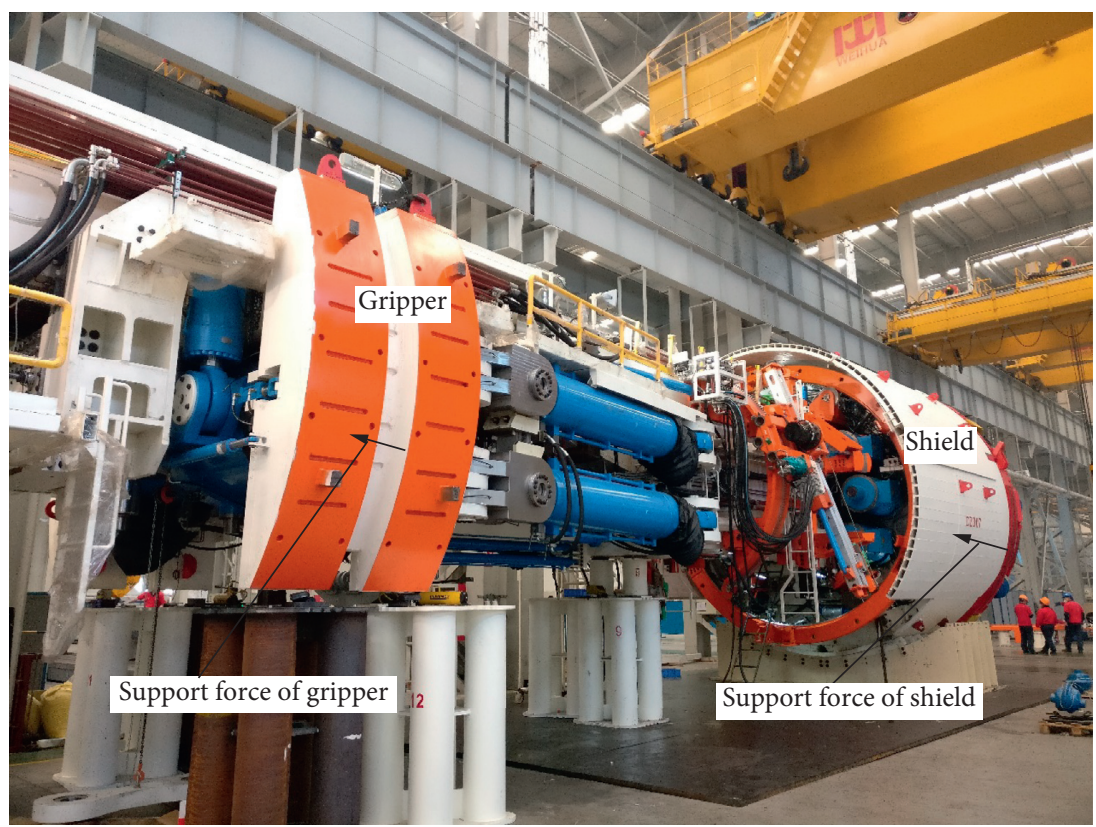

FIgURE 11: TBM schematic diagram of support pressure.
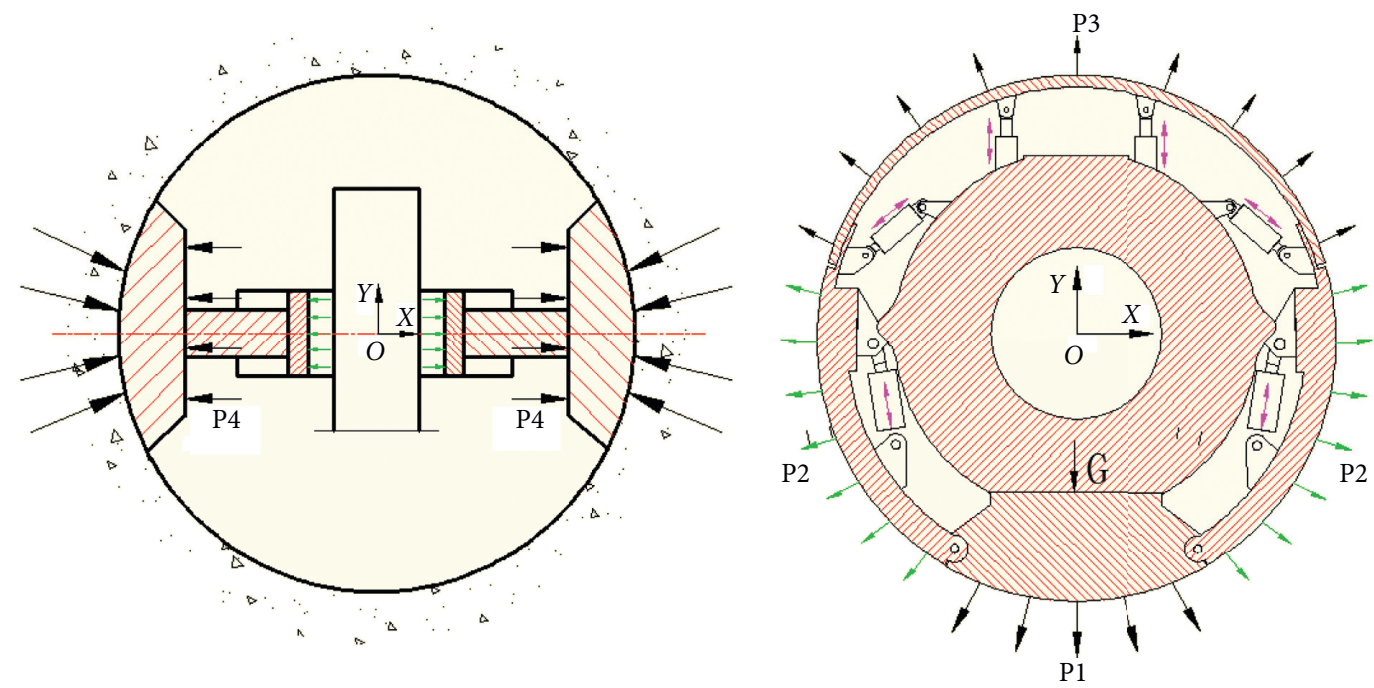

Figure 12: Schematic diagram of supporting pressure.

TABLE 5: Shield-surrounding rock contact stiffness under different shield support pressures.

\begin{tabular}{lcc}
\hline Number & $\begin{array}{c}\text { Support force of shield } \\
(\mathrm{kN})\end{array}$ & $\begin{array}{c}\text { Equivalent stiffness } \\
(\mathrm{N} / \mathrm{m})\end{array}$ \\
\hline 1 & 800 & $5.49 e 8$ \\
2 & 900 & $7.99 e 8$ \\
3 & 1000 & $1.04 e 9$ \\
4 & 1100 & $1.30 e 9$ \\
5 & 1200 & $1.56 e 9$ \\
\hline
\end{tabular}

$285 \%$, respectively. Taking 14,000, 16,000, 18,000, 20,000, and $22,000 \mathrm{kN}$ as the horizontal supporting pressure values, the corresponding contact stiffnesses of the gripper shoessurrounding rock were calculated (Table 6). As the horizontal supporting pressure increases, the gripper shoes-
TABle 6: The gripper shoes-surrounding rock contact stiffness under different horizontal supporting pressures.

\begin{tabular}{lcc}
\hline Number & $\begin{array}{c}\text { Horizontal supporting force } \\
(\mathrm{kN})\end{array}$ & $\begin{array}{c}\text { Equivalent stiffness } \\
(\mathrm{N} / \mathrm{m})\end{array}$ \\
\hline 1 & 14,000 & $2.98 e 10$ \\
2 & 16,000 & $3.43 e 10$ \\
3 & 18,000 & $3.87 e 10$ \\
4 & 20,000 & $4.31 e 10$ \\
5 & 22,000 & $4.75 e 10$ \\
\hline
\end{tabular}

surrounding rock contact stiffness also increases; they increase by $57 \%$ and $59 \%$, respectively.

As seen in Figure 13, the simulation test results of the vibration acceleration reveal that as the contact stiffness on shield-surrounding rock increases sharply, the vibration 


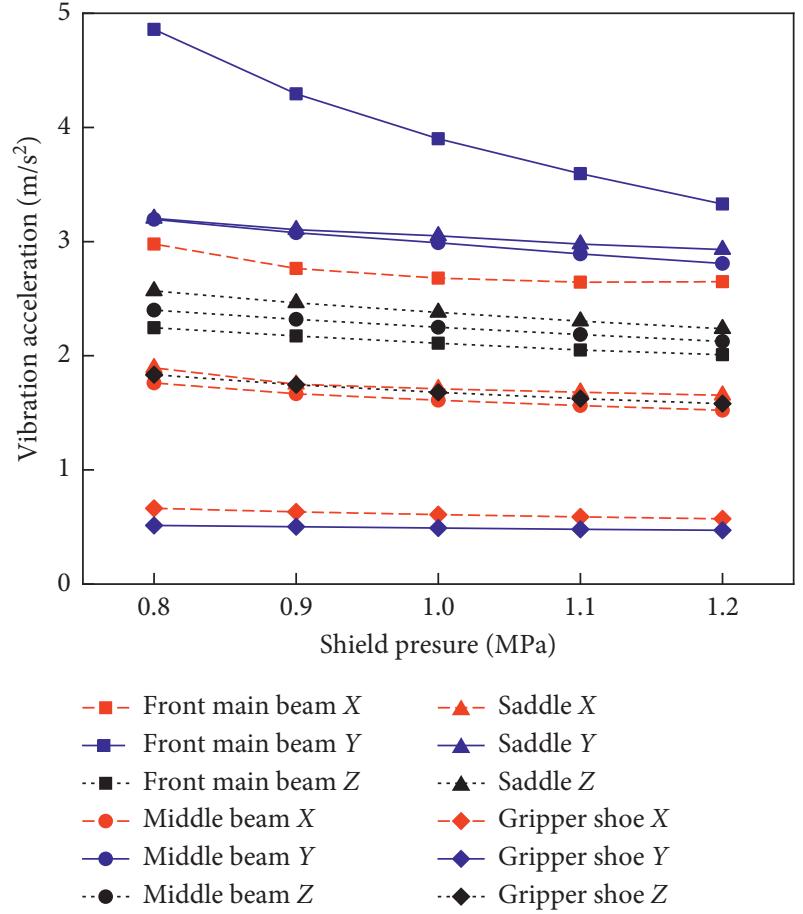

FIgURE 13: Vibration acceleration.

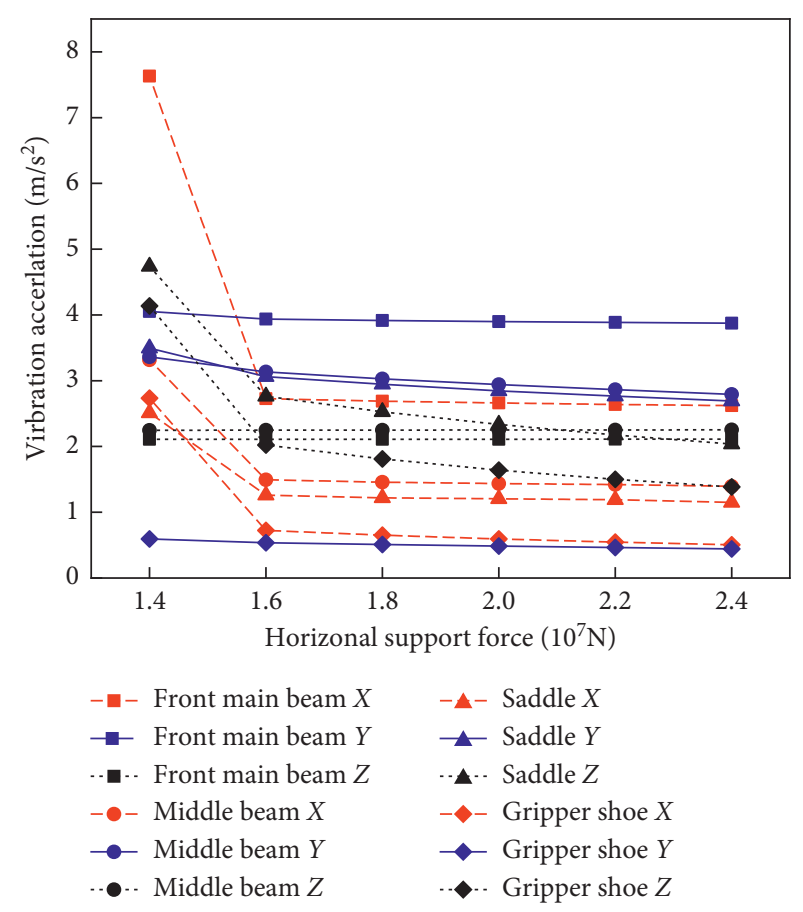

FIgURE 14: Vibration acceleration.

acceleration on all the parts of the supporting-thrusting system display a decreasing trend, but the reduction range is narrow, where the maximum vibration acceleration ( $Y$ direction) of the front main beam, the middle main beam, the saddle frame and the support shoe components are 4.92, $3.25,3.25$, and 0.65 , and the minimum values are $3.5,2.9$, and $3.12,0.63$. Moreover, because the main beam is closer to the shield, the decrease range of the vibration acceleration on the main beam was much more significant than on other parts. However, when the support pressure exceeds $1000 \mathrm{kN}$, the changes in vibration response tend to be slow.

As observed in Figure 14, the vibration accelerations on all the parts of the supporting-thrusting system display a decreasing trend because the contact stiffness on shieldsurrounding rock becomes comparatively higher. The vibration responses of all the parts were the most significant especially when the support pressure changed to $14,000-16,000 \mathrm{kN}$. However, when the support pressure exceeds $16,000 \mathrm{kN}$, the variations in vibration response tend to be insignificant.

Therefore, the support pressure of the force $(1000 \mathrm{kN})$ and horizontal supporting pressure $(16,000 \mathrm{kN})$ were the critical values of influential factors of the vibration response under the working condition.

\section{Conclusion}

(1) The influential factors of vibration response of a TBM supporting-thrusting system, based on the analysis of the structural features and their functions on major components of the supporting-thrusting system, was studied. By varying the main beam length and dimension of the thrusting cylinder, adjusting the support pressure of the shield and horizontal supporting pressure, and setting the parameters of the TBM, the vibration responses to the TBM supporting-thrusting system under various influential factors were obtained by computer simulation.

(2) The longer the length of the front main beam, the smaller the equivalent stiffness of the structure, which increases the support vibration acceleration while gradually reducing the vibration accelerations on the saddle and gripper shoes at the rear area of the front main beam. Considering that the structure of the front main beam is quite monotonous, and there are no vital parts arranged in this area, the product designer may increase the length of the front main beam appropriately. This will help to reduce the adverse effects caused by the vibration to the more vital but vulnerable middle main beam and gripper shoes.

(3) When the stroke of the thrusting cylinder exceeds $1200 \mathrm{~mm}$, the vibration acceleration at the front main beam increases rapidly, and in the process of the TBM moving forward, the control strategy of "first quick and then slow" should be adopted to reduce the peak value of vibration acceleration.

(4) Targeting TBM products of $8 \mathrm{~m}$ diameter, the specification of the thrusting cylinder with $500 \mathrm{~mm}$ diameter is prioritized. The support pressure of $1000 \mathrm{kN}$ originating from lateral shield and the horizontal supporting pressure of $16,000 \mathrm{kN}$ directed from gripper shoes are adopted as the preferred working parameters under such geological conditions. 


\section{Data Availability}

The data used to support the findings of this study are included within the article.

\section{Conflicts of Interest}

The authors declare that they have no conflicts of interest.

\section{Acknowledgments}

This research was supported by the National Key R\&D Program of China (Grant no. 2017YFB1302603), National Natural Science Foundation of China (Grant no. 51905550), and the Major Science and Technology Projects of Hunan Province (no. 2019GK1010).

\section{References}

[1] E. Paltrinieri, F. Sandrone, and J. Zhao, "Analysis and estimation of gripper TBM performances in highly fractured and faulted rocks," Tunnelling and Underground Space Technology, vol. 52, pp. 44-61, 2016.

[2] J. Rostami, "Hard rock TBM cutterhead modeling for design and performance prediction," Geomechanik und Tunnelbau, vol. 1, no. 1, pp. 18-28, 2008.

[3] K. Schaeffer and M. A. Mooney, "Examining the influence of TBM-ground interaction on electrical resistivity imaging ahead of the TBM," Tunnelling and Underground Space Technology, vol. 58, pp. 82-98, 2016.

[4] J.-W. Cho, S. Jeon, H.-Y. Jeong, and S.-H. Chang, "Evaluation of cutting efficiency during TBM disc cutter excavation within a Korean granitic rock using linear-cutting-machine testing and photogrammetric measurement," Tunnelling and Underground Space Technology, vol. 35, pp. 37-54, 2013.

[5] M. Y. Fattah, M. J. Hamoo, and S. H. Dawood, "Dynamic response of a lined tunnel with transmitting boundaries," Earthquakes and Structures, vol. 8, no. 1, pp. 275-304, 2015.

[6] M. Y. Fattah, K. T. Shlash, and M. S. al-Soud, "Boundary element analysis of a lined tunnel problem," International Journal of Engineering, IJE Transactions B: Applications, vol. 25, no. 2, pp. 87-94, 2012.

[7] M. Y. Fattah, K. T. Shlash, and N. M. Salim, Propagation of Plastic Zone Around a Tunnel in Cohesive Soil, The Second Scientific Engineering Conference, College of Engineering, University of Mosul, Mosul, Iraq, 2013.

[8] D. Festa, W. Broere, and J. W. Bosch, "An investigation into the forces acting on a TBM during driving - mining the TBM logged data," Tunnelling and Underground Space Technology, vol. 32, pp. 143-157, 2012.

[9] J. Z. Huo, X. Ouyang, Y. Wang et al., "Analysis of influencing factors of vibration behaviors of TBM cutterhead under heavy impact loads," Journal of Harbin Engineering University, vol. 36, no. 4, pp. 555-559, 2015.

[10] J. Z. Huo, X. Zhang, X. Ouyang et al., "Kinetic modeling and analysis on axial-vertical vibration characteristics for the disc cutter," Machine Design and Research, vol. 30, no. 5, pp. 114-118, 2014.

[11] J. Ling, W. Sun, J. Huo, and L. Guo, "Study of TBM cutterhead fatigue crack propagation life based on multi-degree of freedom coupling system dynamics," Computers \& Industrial Engineering, vol. 83, pp. 1-14, 2015.
[12] W. Sun, X. Ding, J. Wei, X. Wang, and A. Zhang, "Hierarchical modeling method and dynamic characteristics of cutter head driving system in tunneling boring machine," Tunnelling and Underground Space Technology, vol. 52, pp. 99-110, 2016.

[13] J. Hassanpour, J. Rostami, and J. Zhao, "A new hard rock TBM performance prediction model for project planning," Tunnelling and Underground Space Technology, vol. 26, no. 5, pp. 595-603, 2011.

[14] Y. Wu, J. Tao, C. Liu et al., "Stiffness modeling of thrust cylinder in hard rock tunnel boring machine," in Proceedings of the 2015 International Conference on IEEE Fluid Power and Mechatronics (FPM), pp. 157-162, Harbin, China, August 2015.

[15] T. Huang, X. Wang, H. Liu, and Y. Yang, "Force analysis of an open TBM gripping-thrusting-regripping mechanism," Mechanism and Machine Theory, vol. 98, pp. 101-113, 2016.

[16] H. Yu, P. Hao, Y. Zhao et al., "Non-linear behavior of normal contact stiffness of tunnel surface and supporting system of tunnel boring machines," Journal of Mechanical Engineering, vol. 50, no. 21, pp. 54-59, 2014.

[17] Q. Xie and H. Yu, "Coupling relatioanship between loads on cutterhead of Tunnel boring machine and contact stiffness of gripper shoes and rocks," Journal of Shanghai Jiaotong University, vol. 49, no. 9, pp. 1269-1275, 2015.

[18] J. Rostami, "Performance prediction of hard rock Tunnel Boring Machines (TBMs) in difficult ground," Tunnelling and Underground Space Technology, vol. 57, pp. 173-182, 2016.

[19] Y. Wu, H. Yamamoto, J. Cui, and H. Cheng, "Influence of load mode on particle crushing characteristics of silica sand at high stresses," International Journal of Geomechanics, vol. 20, no. 3, Article ID 04019194, 2020.

[20] X. Wang, J. Cui, Y. Wu et al., "Mechanical properties of calcareous silts in a hydraulic fill island-reef," Marine Georesources \& Geotechnology, pp. 1-14, 2020.

[21] L. Wang, B. Wu, R. Du et al., "Nonlinear dynamic characteristics of moving hydraulic cylinder," Chinese Journal of Mechanical Engineering, vol. 43, no. 12, pp. 12-19, 2007.

[22] Y.-h. Park, H.-k. Lee, K.-t. Park, and H.-c. Park, "Practical behavior of advanced non-linear hydraulic servo system model for a mold oscillating mechanism depending on line volume," Journal of Mechanical Science and Technology, vol. 30, no. 3, pp. 975-982, 2016.

[23] P. Hao, H. D. Yu, and Y. Zhao, "Normal stiffness of tunnel surface contacting with thrusting boots of TBM with various surface characteristics," Journal of Shanghai Jiao Tong University, vol. 46, no. 6, pp. 827-832, 2014. 